\title{
A study on Spring Festival belief activities in coastal areas of Shandong--- A Case Study of Qingdao Tianheng Island
}

\author{
Hongjuan Zhao* \\ Qingdao University of Science and Technology, Qingdao, 266061, China
}

Keywords: the spring festival; beliefs; ocean; Tianheng Island

\begin{abstract}
In the coastal areas of Shandong Province, there are many worship services during the Spring Festival. The worship activities are based on the belief of the sea. The gods of its sacrifices can be described as extremely numerous. In addition to their old ancestors, God of Wealth, and heavenly grandfathers, they also sacrifice the fishermen's safety, fishing harvest closely related to Matsu, Hailong, Sun Xianku, four rich, days, master and many other gods, which shows the unique customs of the coastal areas. Based on the investigation of the belief ritual of the spring festival in the Tian heng island area of Qingdao, this paper probes into how coastal fishermen strengthen their sense of identity and belonging to the family and the group, and even enhance the identity of the villages and their living backgrounds by means of various deities and worship of various deities during the Spring Festival.
\end{abstract}

\section{山东沿海地区春节信仰活动研究一一以青岛田横岛为例}

\author{
赵洪娟 (1) \\ （青岛科技大学，青岛，266061）
}

关键词: 春节, 信仰, 海洋, 田横岛

摘要: 山东沿海地区春节信仰祭祀多是以海洋信仰为背景的祭拜活动, 其祭祀的神灵可谓是 极其众多, 除自家老祖、财神爷、天老爷外，还要祭祀于渔民安全、渔业收成密切相关的妈 祖、海龙王、孙仙姑、四财主、天老爷等诸多神灵, 展现了沿海地区独特的信仰风俗。本文 通过对青岛田横岛地区春节信仰仪式的调查, 探讨了沿海渔民是如何借助各种神灵信仰以及 春节时对各种神灵的拜祭增强对家族和集体的认同感与归属感, 甚至增强了对村落及其生活 背景的认同感的。

\section{1. 前 言}

山东青岛、威海、烟台等地濒临渤海, 独特的地理位置孕育了特色的地域风情和风俗文 化。与农业耕种为主的内地相比较, 沿海地区因其渔业生产特征, 形成了独特的海神信仰系 统, 青岛田横岛还产生了中国北方地区最大的祭海仪式---田横祭海节。田横祭海节是具有中 国特色的海洋文化狂欢节, 是人们想摆脱对生产的繁重、生活的困境从而向神灵祈拜丰收与 生活幸福的情感表达。如果说青岛田横祭海节是 “大众狂欢” 的话, 那渔民的春节祭祀则是 一种家族式、集体性的礼典。

\footnotetext{
(1)作者简介：赵洪娟，青岛科技大学副教授，研究方向民俗学、民间文学、丝路文化。 基金项目：本文系 “教育部人文社会科学研究青年基金项目”（项目编号：17YJC770045），2017 年全国高校外语教学科 研项目（2017SD0070B）阶段性成果。
} 
若 “仪式是一个身体经历的过程，人们的身体聚集到一个地点，开始了仪式过程”，[1] 那渔民的春节祭祀可以说是人们的身体和心灵都聚集到了一个共同点, 然后开始了祭祀活动, 这种祭祀具有家族性、集体性，但并不同于村落共同体所开展的民众为获得某种资源、人脉、 礼仪关系所进行的仪式, 而是一种相对纯净的 “精神祈拜” 仪式。

\section{2. 基于海神信仰的祭祀体系}

青岛田横岛位于东濒黄海，南依崂山的即墨，即墨因临近墨水河而得名。田横岛，位于 即墨市洼里乡东部海面 3.5 公里处, 是面积为 1.4 平方公里的东西狭长岛屿。这是一座历史 悠久的名岛, 据《史记》记载, 秦末汉初刘邦称帝, 遣使诏齐王田横降, 田横在赴洛阳途中 自刎。岛上 500 将士闻此哥耗, 集体挥刀殉节, 世人感 500 将士之忠烈, 遂命名此岛为田横 岛。[2]

海洋不同于陆地, 其受气候、海风等自然力影响较大, 变化莫测, 渔业生产因此具有不 稳定性。在这种不安定的环境中人们对平安祥和的需求极为迫切, 这种心理使他们依赖信仰 的意志更为强烈。于是为了求得生存平安便将精神、心灵寄托于神灵, 以祈求平安幸福, 海 洋祭祀体系便有了其构建的前提和条件。

田横地区春节时祭祀的神灵可谓是极其众多，除了自家老祖，即已去世先辈和财神爷、 天老爷外, 还要祭祀于渔民安全、收成密切相关的妈祖、海龙王、孙仙姑、四财主、天老爷 等诸多神灵。渔民的海神信仰只求其灵验性及心中慰藉, 并不追求神灵的来源属性, 所以 “一个人同时崇拜很多神, 上午进佛庙, 下午进道观, 并不觉得冲突” [3]。由于神最初是由 人类的恐惧制造出来的, 海神信仰从人们对海神的恐惧、崇拜发展到对海神的祈求, 反映了 海神信仰的强烈的功利性, “所谓功利性是指任何形式的海神信仰都是在实用、功利目的这 一基础上发生和发展起来的” [4]。正如马林诺夫斯基所言： “人类为平衡和契合人与周围环 境之间的密切关系, 借助仪式庆典来稳定这种密切关系, 对天然富饶的力量获得相对稳定的 控制” [5]。从总体上讲, 田横地区以海洋信仰为背景的祭祀活动, 是一种民俗性的, 而非 宗教性的海神祭祀活动, 其祭祀仪式是一种地方风俗的展现。

\section{3. 青岛田横春节信仰祭祀仪式过程 ${ }^{(1)}$}

（一）恭请“老祖”过大年 每年的除夕之日，各家的妇女都在家中准备过年的菜肴及 各种供品, 而在海上劳作了近一年的男性渔民们则在这合家团聚的日子里要去各家的坟莹上 恭请自己的“老祖”回家过年。笔者所调查的田横周戈庄村的村民大多姓刘, 都是刘姓家族, 但谱系又有细分，亲疏关系实则不同。以前家族人口多，恭请“老祖”回家过年时大多堂兄地 多人一起去坟茥上恭请老祖，将“老祖”请到家族“家庙”，亦称“庙堂”之中进行团聚。后来文 革时期“破四旧”，“家庙”大多被损坏，接下来随着人口的减少，渔民们基本上都是各家恭请 自己的“老祖”回自己家过年，不再是一大家子人“齐伙伙”的一起请了。据刘广年老人介绍， 现在一般都是各家的男人带着自己的儿子或闺女到坟莹上去请“老祖”回家，“以前只能是男 孩跟着父亲去上坟, 现在无所谓了, 有小闺女的人家如果小闺女愿意跟着去, 也一起带着, 这也是对老祖的恭敬, 老祖看着男男女女的小孩子也觉得欢快”。据调查, 在山东内陆很多 地区, 女孩现在仍然是不能跟着父辈到祖坟上去烧香、请祖的，女孩在从事的许多事情上仍 有诸多禁忌，而田横岛渔民的不同做法反应了胶东一带沿海地区渔民的思想更加的包容开放。

“老祖”请回家后将会被供奉在“正间”，即堂屋正北的位置，北墙上还需挂上家谱，家 谱下面的供桌上摆放“三代宗亲之位”的牌位, 在牌位前摆放好各式供品, 有鱼、肉、馒头等

(1) 本次田野调查主要采访了田横镇周戈庄村的刘广年。

老人, 66 岁，从事海上捕鱼近 40 余年，周戈庄村民俗协会会长。

(2) 讲述者: 刘广年老伴, 王桂珍, 65 岁。 
旧时不能常吃到的各式美味菜有，同时需要摆放四双碗筷，而非一双或两双。四双的含义一 来表示“成双”，二来寓意本家“人口众多”。一般人家的供奉桌需持续的正月十六日，年真正 结束后才会将其撤掉。

随着时代的变迁，我们在谈论年味越来越淡，越来越没有过年的感觉时，当地渔民却说 请“老租”回家过年或其他各种祭祀仪式让他们感觉年味没有变，信仰仪式就是他们心中的年 味，在近几年有几个村还建立了庙堂，请“老祖”到家族庙堂过年，“有了家庙就又成了一大 家子人了, 老祖回来有地方去, 大家也都觉得亲近, 特别是过年的时候, 叔伯侄辈等一起拜 老祖, 互相走动, 特别亲近”(1), 由此可见信仰的确在很大程度上表现了“仪式和实践的用途”。 （二）面向东北迎财神 “老祖”请回家之后，便要请财神进门。请财神这一习俗全国各 地许多地方均有保留, 田横地区也不例外。据刘广年老人说“农民拜财神, 请财神, 我们渔 民同样也要祭拜，财神是天下所有老百姓的财神”。但在田横地区，请财神的位置特别有讲 究, 一定要面向东北的方向“发香火”, “请财神”。老人说因为财神住在东北方位, 所以要面 向这个方位进行恭请。实际上, 面向东北的主要原因可能由于我国海洋大多位于东部地区, 同时田横镇的东北海域尤其发达，渔民祖祖辈辈出海捕鱼主要朝东北方向开进。

财神请回家后渔民们就觉得安心了许多，财神进家了，来年渔业必定有个好收成。

（三）供拜“天老爷” 财神请回家后就要给天老爷“摆供”了，即为天老爷摆好牌位，放 好供品, 有些人家也会在给天老爷摆完供品后再去门口面向东北方向恭请财神, 这个次序先 后是没有严格要求的。天老爷是中国民众民间信仰的重要神灵，这个神灵并非是道教或其他 宗教中人神共一的某一信仰的主体，天老爷是没有人格化构建之神，没有具体形象，其功能 主要是保佑船家网网有收获, 回回船满仓。天老爷因为其特殊重要的地位和作用, 渔民们认 为其就是“玉皇大帝”，地位尊贵，因此要在“天井”，即院子的南面为其搭建小棚屋以进行供 奉, 同时还需要在小屋内摆放黄色的牌位, 以示其尊贵。玉皇大帝的面前摆放一双碗筷, 以 表示其一人食用所有供品。天老爷的供桌摆放好后需要在“正间”屋子朝东方向摆放绿色的 “东厨司命德之位”，其灶王爷的牌位。在灶王爷牌位前需摆放三双碗筷，据渔民说灶王爷有 两位夫人, 三双碗筷必不可少。

在田横地区，供奉“老祖”，“天老爷”，“灶王爷”都需要有牌位，而且不同的牌位有其固 定颜色, 天老爷的牌位是黄色的, 灶王爷的牌位是绿色的, 老祖的牌位是暗红色的。据当地 渔民介绍, 不同颜色其实并没有什么特别的讲究, 主要原因是以前渔民不识字, 用颜色来区 分不同牌位主要是便于识别，以防在供摆时将其弄混。

（四）给龙王“发香火” 田横地区春节时期祭祀的主要神灵是海龙王。佛教中有关于龙 王“勤力兴云致雨”的说法，这一说法的兴盛主要与汉代以后佛教传入中国有关。此外在内地， 民间有向龙王祈雨的习俗, 龙王因为有管理雨的功能, 沿海地区渔民便把龙王当作海神崇拜, 成为渔民信仰中的最重要神灵。在即墨田横镇, 30 个村中有 18 个村是渔村, 每个渔村都有 龙王庙, 周戈庄的龙王庙是最大的, 里面供奉的是龙王、赶渔郎和女童子。龙王庙的祭祀主 要包括春节、第一次出行前的祭海以及龙王的生日。“发香火”的主要方式就是到龙王庙中去 进香祈拜，庙前燃放鞭炮，以便让龙王知晓渔民的诚心信奉。

（五）敬奉妈祖娘娘 中国南方地区有信仰海神妈祖的习俗，而北方一带主要信奉海龙 王, 但随着中国南北方文化的交流, 妈祖也成为田横一带信仰的重要神灵, 毗邻龙王庙的天 后宫, 即妈祖庙也随之建立起来了。在田横地区妈祖神的功能意义与南方有稍许不同, 据刘 广年老伴王桂珍说“妈祖娘娘能给妇女看病, 妇女们有些什么小毛病都去求妈祖娘娘, 你想 想要是男人去海了, 女人们有个小灾小病的去求谁啊, 龙王庙和妈祖庙并排挨着, 龙王是男 的有些话也不好说，所以妇女都爱去求妈祖，女人之间好说话。”通过王桂珍的讲述，我们 可以感受到妈祖在当地女性心中一方面是需要敬奉, 看不见摸不着的神灵, 另一方面却是她 们的知心人，将妈祖看作是与其同样能感受到其不同情感的“女人”，此时神被真正的人格化

(1) 讲述者: 刘广年。 
了, 这一点区别于保佑渔民安康丰收、一直被当作神灵供奉的海龙王。过年这天，女人们由 于在家忙年，一般多由男性去妈祖庙送香火，而平时妈祖庙当地女性祈拜较多。

去龙王庙和妈祖庙“发香火”时一般多是几家结伴一起, 多以一个小家族居多。这种祭祀 活动在他们眼中就是一种神圣而严肃的仪式, 具有较强的神圣感, 这个仪式让他们觉得整个 家族亦或是整村渔民都是一家人, 一个整体, 龙王妈祖将保佑他们这个整体的平安、富足, 此时他们的归属感和集体感将大大增强。

（六）正月初一拜“财主”

此外, 田横一带的民众还信仰狐仙四财主。狐仙信仰始于唐代, 人们认为狐仙可致福祸, 此信仰在中国北方一带非常流行, 体现了农业社会民众对动物崇拜的反映。在这种信仰崇拜 的基础上不免有各种神话传说产生。相传狐仙四财主长得如猫般大小, 但由于其膝盖骨犹如 人一般是朝前的, 这点有别于其他四条腿的动物, 因为四腿动物膝盖均是朝后。四财主的主 要法力是治病, 可帮渔民解除各种病痛, 同时还可帮渔民避开海难, 可谓是救助危难、保护 平安的神灵。据周戈庄三四十里地的地方有座南山, 是当地海拔最高的一座山, 在这座上的 山顶上有个山洞, 相传是四财主修炼成仙的地方。在 20 世纪中期之后, 由于破除迷信活动 的开展, 狐仙崇拜的习俗也逐渐消失了。近些年随着四财主的信奉之俗在当地又重新兴盛起 来，田横镇渔民在年初一会争先恐后地对四财主进行祭祀，以求平安。

敬奉天老爷，迎财神、给龙王、妈祖送香火等事情多由家中年长些的人去做，“小年轻 儿”，即未成家或刚成家的人做的较少。而初一拜“四财主”则多是年轻人的事儿，老年人一 般不参与。正月初一一大早, 年轻人便结伴一起, 带着黄酒去祈拜“四财主”, 他们来到“四 财主”的洞前, 将黄酒倒进碗里, 然后嘴中念叨“四财主帮我爸爸治治 XX 病”, “帮我妈妈治 治 XX 病”，念叨完之后便离开，意思是“四财主”要往黄酒碗里放治疗其父或其母之病的药 物了, 因不能偷看, 只好暂时离开。过一会儿之后, 年轻人便将这碗黄酒带回家中让其父母 饮用, 所以祈拜过“四财爷”的年轻人都觉得祈拜之后他们的黄酒变得非常浑厚、浑浊, 神灵 定是放了各种药物进去。

现在初一拜“四财主”的风俗在当地非常兴盛, 除却迷信的说法, 当地渔民认为这是年轻 人对老人表达孝心和关爱之情的一种体现，里面包含的弄弄亲情和爱意值得珍藏和发扬。

在年轻人眼中，拜“四财主”是他们这一群体在过年时的一个共同仪式，不是单纯的个人 行为, 而是一种宗族式或集体进行的共同行动。因此自己堂兄弟姊妹多结伴而行, 同去拜祭, 他们认为做这个事情是有价值、有意义的，奔向一个共同目标，并定有其效果，心里的慰藉 和满足感大大增强了。

\section{（七）正月初二拜“仙姑”}

在田横一带还有仙姑的传说。仙姑姓孙, 她聪明伶俐、乐于助人。成年许配之后还未过 门其丈夫便去世了, 但孙姑娘生性善良主到要求去婆家伺候婆婆, 但受到婆婆各种虐待, 后 来自我修炼成仙经常帮助渔民躲避各种灾难, 深受民众喜爱。传说她去世那年, 在一条船遭 遇海难的前一天, 孙姑娘托梦于船老大, 使船老大及其他成员避开了海难。后来, 船员们为 报救命之恩, 依据船老大梦中的记忆, 找到了孙姑娘的家乡, 发现此村果真有孙姑娘其人, 认为孙姑娘对民众有救施、帮扶之能, 是位神灵, 理应受到敬重, 成为保佑民众平安的仙姑。 孙仙姑是周戈庄祭祀的重要神灵, 虽不是全国性普遍信仰的神灵, 但对当地渔民来说其对仙 姑的信仰程度可能仅次于龙王。在周戈庄不远处还有个仙姑岛, 仙姑岛上的庙宇是妇女常去 祈拜的地方。

在田横当地一般女性会在初二，忙完年之后，有些许空闲了去拜祭“仙姑”。拜见“仙姑” 时也并不是单个人拿着供品、香、纸等物前去仙姑岛摆祭或发香火, 而是多位女性相约结伴, 一同前行。正如王桂珍所言 “男人过年那天去龙王庙、妈祖庙发香火, 女人在家准备过年的 东西, 等初二的时候, 女人空闲下来了, 就噶胡着一块儿（结伴一起）去拜孙仙姑。这事儿 可正式了, 一块儿去拜仙姑, 就是平常爱吵吵的两个人, 现在也不吵吵了, 挺好的, 挺团结 
的。”可见, 春节时期的这种祭祀, 用共同的情感将渔民凝聚到了一起, 让他们在心灵与实 际行动上都形成了一个整体，不断衍生出新的认同感、归属感。

总之，海神是沿海民众根据生产生活想象出来的崇敬海洋的神灵，海龙王的崇信是青岛 沿海各地各种传说的起源, 后来又逐渐演化出四财爷、孙姑娘、妈祖等神灵, 由此形成了完 整的海洋信仰谱系，同时这些神灵也是沿海神话和传说的载体。

渔民所崇信的各神灵是“人类向海洋发展、开拓、利用的过程中对异己力量的崇拜，也 就是对超自然和超社会力量的崇拜”[6], 在上述海洋信仰体系中, 龙王、妈祖等神灵属于全 能之神, 既可求吉保平安, 又可避难禳灾, 同时还有保生育治疾病之功能。此外, 海神信仰 可以提升族群的凝聚力, 并通过相应的祭祀仪式体现出来, 这些仪式“具有整合的力量, 其 功能在于它将所有的人连接起来, 宣扬社区中共有和相似的文化遗产, 缩减社群中的差异, 并使他们的思想、情感与行为变得相近, 从而有助于社会凝聚" " [7]。因此便很自然地由海洋 信仰、崇祭演化出相应的庆典, 正如泰勒所言“宗教仪式既有象征意义又有实际意义, 其形 式会一直重复, 直到内在意义发生变化为止" ${ }^{[8]}$ 。

\section{4. 讨 论}

与以农耕为主的内陆地区相比较, 沿海地区的春节信仰祭祀具有其独特特征, 主要表现 在如下几个方面。

（一）信奉神祗的多样性。内陆地区在春节期间主要祭祀财神、灶神、天老爷及祖先， 而沿海地区除祭祀内陆民众信奉的神祇外, 还要祭祀主管渔业生产及渔民安危的海龙王和妈 祖，可谓是多神供奉。在辞旧迎新的年节这一阈限时期，在“过年”这一“边缘礼仪”[9]进行的 时刻, 由于渔业生产的特殊危险性和早期渔民对自然灾难认知的局限性, 在渔民心中海龙王 等可以禳灾聚福的海洋神祗的意义远远大于其他神灵, 这就是缘何渔民需在除夕之日去龙王 庙、妈祖庙摆供、“送香火”之因由。

（二）地域性民间俗信的崇祭。除了祭祀龙王、妈祖等全能之神外，四财主、孙仙姑等 人格化的, 具有地域特色的传说神灵也是春节期间渔民祭祀的重要对象, 这点有别于年节时 主要祭祀财神、灶王和祖先神灵的其他地方。此外，对人格化的传说神灵的拜祭主体亦是有 一定的类别性和多样性, 如祈拜四财主的主要是年轻人, 拜奉四仙姑的主要是女性。至于孩 童，现在无论男女均可跟随家中父兄去龙王庙、天后宫“发香火”，去祖上坟茥请“老祖”回家 过年, 亦或跟随年轻人登南山拜财主, 跟奶奶妈妈婶婶去仙姑岛烧香祈福, 没有严格的规则 限制。如上区别于内陆地区的种种做法反应了在多种不可预知的海洋灾害面前, 胶东一带沿 海渔民信仰的包容性, 男女老少期盼平安丰收的共同的、强烈的愿望, 为实现祛灾祈福的目 的，在信仰祭祀中不排斥女性以及孩童参与其中。

（三）宗族式、集体式（团体式）信仰祭祀。如果说田横祭海节在政府的支持参与下已 变成一场盛大的“狂欢节” 的话, 而此地区渔民的春节祭祀多是一种宗族式的, 更加真诚且 并未加入太多表演成分的一种民间信仰。随着时代的发展, 体制的更新改革, 家族、谱系关 系在村民生活中大多逐渐变淡, 而在山东渔村这种家族谱系关系仍然十分密切, 究其原因, 可知春节祭祀是勾连、固定家族关系的一种纽带, 也可谓是一种小型的集体仪式。正如韩敏 所言, “全新构筑家族组织和传统仪式是农民对经济和社会变化做出的具有创造性的回应”[10]。 这种创造性的回应并不是单指为了共同的经济利益所做出的回应, 同时也是为了密切家族成 员的关系所做出的一种回应。在许多家族中，叔表亲之间平时联系并不太多，他们之间的情

\footnotetext{
(1) 布朗曾说: “信仰在很大程度上表现为仪式上和实践上的用途”。田横祭海节已不再是过去单纯的海洋信仰的节日, 而 是成为一种海洋旅游文化盛宴, 政府希望利用丰富的海洋资源和传统民俗开发旅游业, 以促进经济发展, 增加民众收入。 由政府参与的田横祭海节在保留了对可保佑丰收、平安的五大神祇的传统祭祀内容的同时还增加了京剧、舞狮子、扭种歌、 撒豆舞、和驱除邪恶的傩舞等舞蹈以及其他各式各样的艺术表演、大型晚会, 以及艺术品展示等多种活动。同时开拓出各 种市场以出售各式海产品和手工艺品。
} 
感关联也并非十分密切，而春节祭祀活动则让他们重新聚集到了一起，让分离半年甚至一年 的疏离关系得到修整，对其而言这也是人生的一种特殊情感和体验。由于春节之后渔民都要 出海打渔，各自忙碌，因此春节的集聚，特别是因某种目的从事某个共同事件时，他们找到 了共同的归属感，这种归属感、这种心灵上的连接让渔民们在忙碌艰辛的生活之外找到了一 份心灵上的安静与满足。实际上，在渔民心中，春节信仰多已不再具有真正的“准”、“灵”之 功能，更多的则是一种美好期许与心灵慰藉。

\section{References:}

[1] Randall Collins. Interaction Ritual Chains. Translated by Lin Juren , Beijing: The Commercial Press, 2009, P93.

[2] Tianheng Compilation Committee. County Annals of Tianheng. Jinan: Shandong Map Press, $2008, \mathrm{P} 211$.

[3] Gao, W. Research on Belief and Custom of Wenchang. Chengdu: Sichuan Press, 2008.

[4] Qu, Jinliang. Introduction to Marine Culture. Qingdao: Ocean University of China Press, 1999, P167.

[5] Malinowski. A scientific theory of culture and other essays. New York: Oxford University press, 1960.

[6] Durkheim, Emile. Trans. Joseph, W. S. The Elementary Forms of the Religious Life. London: George Allen \& Unwin LTD., 1964, P36.

[7] He Zhangrong. A probe into the relationship between folk beliefs and contemporary society-- $A$ Probe into the Relationship between Folk Beliefs and Contemporary Society: Reflections on the Field Investigation of Folk Beliefs in Zhongshan in Guangdong Province. Academic Research ,2010(3).

[8] Tylor, E. B. Primitive Culture. London: Cambridge University Press, 2007, P335.

[9] Zhang Juwen. Reconsider the "marginal etiquette" in "transition etiquette" mode. Forum on folk culture, 2006 (3).

[10]Han Min. Responding to Revolution and Reform: Social Changes and Continuation of Li Village in Northern Anhui Province. Translated by Lu Yilong and Xu Xinyu. Nanjing: Jiangsu Renmin Press, 2007, P256. 